NOAA

National Marine

Fisheries Service
Fishery Bulletin

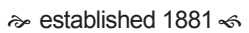

Spencer F. Baird

First U.S. Commissione of Fisheries and founder of Fishery Bulletin
Abstract-Seasonal and annual marine growth of chum salmon $(\mathrm{On}$ corhynchus keta) from Fish Creek, Alaska, during 1972-2004 and from Quilcene River, Washington, during 1973-2004 were examined in relation to abundances of chum salmon and pink salmon (O. gorbuscha) and climate indices from that period. Pink salmon abundance indices were included in the analysis because of evidence for density-dependent effects on chum salmon growth and survival. In linear regression models, growth was negatively related to abundance of chum salmon or to the combined abundance of pink and chum salmon during the middle juvenile (July-Sept), $1^{\text {st }}$ immature, $2^{\text {nd }}$ immature, and maturing stages for the Fish Creek chum salmon and the $1^{\text {st }}$ immature, $2^{\text {nd }}$ immature, and maturing stages for Quilcene River chum salmon, indicating possible density-dependent effects on growth. Mid-juvenile and maturing growth models for the Fish Creek chum salmon and the maturing growth model for Quilcene River chum salmon performed well in model validation, when model predictions were tested against $20 \%$ of the data that were not used for model specification, and provided insight into the effects of climate and abundance on growth of chum salmon from 1972 to 2004 .

Manuscript submitted 30 June 2015. Manuscript accepted 5 February 2016. Fish. Bull. 114:203-219 (2016).

Online publication date: 3 March 2016. doi: $10.7755 /$ FB.114.2.7

The views and opinions expressed or implied in this article are those of the author (or authors) and do not necessarily reflect the position of the National Marine Fisheries Service, NOAA.

\section{Effect of population abundance and climate on the growth of 2 populations of chum salmon (Oncorhynchus keta) in the eastern North Pacific Ocean}

\author{
Ellen M. Yasumiishi (contact author) 1,2 \\ Keith R. Criddle ${ }^{1}$ \\ John H. Helle ${ }^{1,3}$ \\ Nicola Hillgruber ${ }^{1,4}$ \\ Franz J. Mueter ${ }^{1}$ \\ Email address for contact author: ellen.yasumiishi@noaa.gov \\ ${ }^{1}$ University of Alaska Fairbanks \\ School of Fisheries and Ocean Sciences \\ 17101 Point Lena Loop Road \\ Juneau, Alaska 99801 \\ 2 Auke Bay Laboratories \\ Alaska Fisheries Science Center \\ National Marine Fisheries Service, NOAA \\ Ted Stevens Marine Research Institute \\ 17109 Point Lena Loop Road \\ Juneau, Alaska 99801-8626 \\ 32427 O'Day Drive \\ Juneau, Alaska 99801 \\ 4 Thünen-Institute of Fisheries Ecology \\ Wulfsdorfer Weg 204 \\ 22926 Ahrensburg, Germany
}

Over the last century, the quantity of chum salmon (Oncorhynchus keta) and pink salmon (O. gorbuscha) available for harvest in North America has fluctuated on a multidecadal scale with harvest peaks in the 1930s and the 1990s and lows in the 1950s, 1960s, and 1970s (Eggers et al. ${ }^{1}$; Ruggerone et al. 2010). From the mid1970s to the mid-1990s, increases in salmon production were attributed to a combination of causes: namely of hatchery supplementation (Eggers, 2009), increased survival of wild stocks due to favorable ocean conditions (Beamish and Bouillon, 1993; Francis and Hare 1994; Hare and Francis, 1995; Hilborn and Eggers, 2000; Morita et al., 2006), and improved management of wild stocks (Wertheimer, 1997).

Concurrent with increases in

${ }^{1}$ Eggers, D. M., J. R. Irvine, M. Fukuwa$\mathrm{ka}$, and V. I. Karpenko. 2005. Catch trends and status of North Pacific salmon. NPAFC Doc. 723, Rev. 3, 35p. salmon production from the mid$1970 \mathrm{~s}$ to the mid-1980s and $1990 \mathrm{~s}$, reductions in the average body size were observed in Pacific salmon from North America and Asia (Bigler et al., 1996; Helle and Hoffman, 1998; Bugaev et al., 2001), indicating possible density-dependent effects on growth in the ocean. Based on these correlations, a hypothesis was formulated that there might be a finite carrying capacity for Pacific salmon in the North Pacific Ocean, limited by the amount of food available to support fish growth (Helle and Hoffman, 1998).

Density-dependent influences on growth have been well documented for salmon in the Pacific Ocean. Juvenile pink and chum salmon have a high degree of overlap in diet off southeast Alaska and within Prince William Sound in the Gulf of Alaska (GOA) (Auburn and Ignell, 2000). The marine survival of chum salmon and stomach fullness of juvenile chum 


\section{Table 1}

Hypothesized mechanisms and effects (positive [+] and negative [-]) of selected climate indices on the marine growth of chum salmon (Oncorhynchus keta) in the North Pacific Ocean. Locations are the Gulf of Alaska (GOA), central subarctic North Pacific (CNP) and eastern subarctic North Pacific (ENP) oceans, and Washington (WA). Abbreviations include the mixed layer depth (MLD), Pacific Decadal Oscillation (PDO), and sea surface temperature (SST).

\begin{tabular}{|c|c|c|c|c|}
\hline Stage & Location & Index & Mechanism & Effect \\
\hline \multicolumn{5}{|c|}{ Fish Creek, southern Southeast Alaska (saltwater entry from February through May) } \\
\hline Early juvenile & GOA shelf & Spring wind & Plankton bloom & - \\
\hline Midjuvenile & GOA shelf & Winter MLD & Nutrients availability & + \\
\hline Late juvenile & GOA shelf & Fall wind & Fall bloom & - \\
\hline Immature/maturing & CNP ENP & Winter PDO & Cool, high nutrients+ & \\
\hline Immature/maturing & CNP ENP & Summer SST & Warm & + \\
\hline \multicolumn{5}{|c|}{ Quilcene River, Washington (saltwater entry in May) } \\
\hline Early juvenile & WA coast & Upwelling index & Nutrient upwelling & + \\
\hline Early juvenile & WA coast & Spring transition & Later upwelling & - \\
\hline Midjuvenile & GOA shelf & Winter MLD & Nutrients availability & + \\
\hline Late juvenile & GOA shelf & Fall wind & Plankton bloom & - \\
\hline Immature/maturing & CNP ENP & Winter PDO & Cool, high nutrients & + \\
\hline Immature/maturing & CNP ENP & Summer SST & Warm & + \\
\hline
\end{tabular}

salmon was negatively correlated with the number of fry releases from the hatcheries in coastal waters of Japan (Fukuwaka and Suzuki, 2000). Chum salmon switched from eating crustacean to gelatinous zooplankton when pink salmon were more abundant (Tadokoro et al., 1996). For chum salmon in the eastern Bering Sea, a significant negative relationship was observed between catch-per-unit-of- effort of chum salmon and the mean growth rate for age 0.2 and age 0.3 chum salmon (Azumaya and Ishida, 2000). These observations of prey switching, diet overlap, reduced feeding, and survival success at higher salmon population levels all provide support for the hypothesis that a carrying capacity may exist for salmon in the North Pacific Ocean.

During their marine life, chum salmon from Oregon to the Alaska Peninsula are found primarily in the Alaska Gyre of the eastern North Pacific Ocean (Myers et al., 2007). In the first year at sea, juvenile chum salmon migrate with the counterclockwise Alaska Coastal Current along the Alaska coastline above the continental shelf (Hartt and Dell, 1986). At a velocity of $10 \mathrm{~cm} / \mathrm{s}$, we estimated that the Alaska Coastal Current is able to transport juvenile salmon over $1000 \mathrm{~km}$ in about 4 months, the approximate distance from Washington (WA) to southern Southeast Alaska (Reed and Schumacher, 1986); however this estimate was based on limited data. During the fall, juvenile pink and chum salmon migrate west and southwest along the Alaska Peninsula where they enter the swift westward flowing Alaska Stream $(40 \mathrm{~cm} / \mathrm{s}$ ) (Reed and Schumacher, 1986). During their second through penultimate years at sea, immature northeastern Pacific chum salmon were primarily distributed to the north and east of the western $\left(160^{\circ} \mathrm{W}\right)$ and southern $\left(50^{\circ} \mathrm{N}\right)$ boundaries of the GOA in the eastern North Pacific Ocean (Myers et al.,
2007). During their final year at sea, maturing salmon migrate through oceanic and continental shelf habitats to return to freshwater to spawn. In some years, immature and maturing southern North American stocks of chum salmon move into the Bering Sea in late summer and fall (Seeb et al., 2004). Because chum salmon occupy different regions of the North Pacific Ocean during their ontogenetic migration after first entering the marine realm until their return to their natal streams, it should be possible to develop habitat-specific growth models that could be used to explain variations in growth at each life stage.

Various hypotheses and mechanisms for climate to affect habitat-specific marine growth of chum salmon in the North Pacific Ocean are listed in Table 1. We expected an increase in growth of chum salmon in the eastern North Pacific Ocean to be associated with increased ocean productivity due to a stronger spring phytoplankton bloom as indexed by reduced wind speed (Spies and Weingartner, 2007). Growth was also expected to increase with the occurrence of a fall bloom, increased coastal upwelling, and an earlier timing of spring coastal upwelling (Logerwell et al., 2003). During summer, growth was expected to increase with a deeper mixing layer in the northern GOA during winter that enhances mixing of nutrients and a stronger spring bloom and enhanced summer feeding for juvenile salmon (Sarkar, 2007). Offshore, growth was expected to increase with warmer ocean temperatures (Martinson et al., 2008, 2009) and increased productivity offshore as indexed by the winter Pacific Decadal Oscillation (Mantua et al., 1997).

For this study, we attempt to explore density-dependent and climate limitations on growth for different life stages of chum salmon by examining the effects 


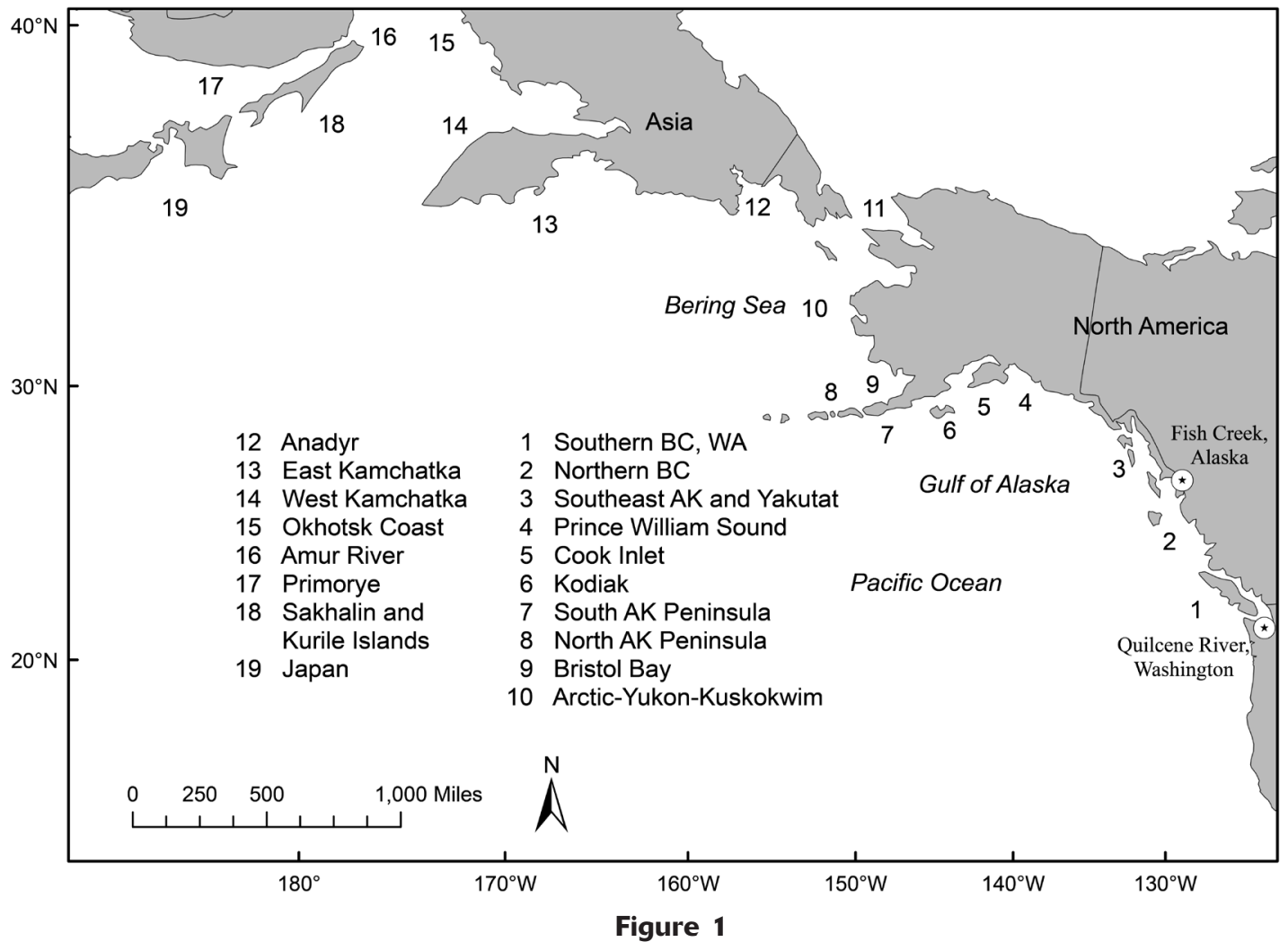

Map showing the regions used to estimate chum salmon (Oncorhynchus keta) and pink salmon $(O$. gorbuscha) abundances (from Ruggerone et al. [2010]) and locations of Fish Creek, Alaska, where biological data were collected from 1972 to 2007, and Quilcene River, Washington, where biological data were collected from 1973 to 2007.

of pink and chum salmon abundance and climate on stage-specific growth of these fish in those portions of the North Pacific Ocean that they occupy. The null hypothesis was that growth was not negatively related to an index of pink and chum salmon abundance and therefore chum salmon production was not limited by density-dependent growth in the North Pacific Ocean. The alternative hypothesis was that growth was negatively related to pink and chum salmon abundancean indication that chum salmon production was limited by density-dependent growth in the North Pacific Ocean. Our objectives were 1) to determine the existence and magnitude of density-dependent growth, 2) to describe differences in density-dependent growth for chum salmon from WA and southern southeast Alaska, 3) to evaluate the influence of pink and chum salmon abundances on chum salmon growth, 4) to evaluate the influence of local and regional abundances on growth, and 5) to determine the influence of climate on growth.

\section{Material and methods}

\section{Data, sample size, and assumptions}

The National Marine Fisheries Service, Auke Bay Laboratories scientists collected biological data from sum- mer chum salmon in Fish Creek near Hyder, Alaska, from 1972 to 2007 and from fall chum salmon from the Quilcene River and U.S. Fish and Wildlife's Quilcene National Fish Hatchery near Quilcene, WA, from 1973 to 2007 (Fig. 1). Fish Creek chum salmon were sampled from mid- to late-August, the peak of the summer run. Quilcene River chum salmon were typically sampled during the first two weeks of December, the peak of the fall run. Although Fish Creek chum salmon returned to spawn earlier in the year, they were larger at maturity than Quilcene River chum salmon.

Scales, body lengths, and sex data were collected from up to 300 chum salmon carcasses per year from both stocks. The aim was to obtain 50 samples for each sex and for the dominant age classes: age-0.2, age-0.3, and age 0.4. Salmon ages were denoted with the decimal method $(x . y)$, where $x$ is the number of winters spent in freshwater after spending a winter in the gravel and $y$ is the number of winters spent in the marine environment. For this study, we used only age 0.3 male chum salmon to reduce variation in growth because of differences in growth between sexes and ages, and because of data availability. Only age-0.3 chum salmon were sampled in some years and we have larger sample sizes for males than females. We sampled during the peak of the spawning migration and the samples represented the dominant age class at that time. Typi- 
cally, the growth and size of male and female salmon covary over time, although at different scales; therefore inclusion of models and discussion for both sexes would be redundant. Body length (nearest $1.0 \mathrm{~mm}$ ) measurements were from the middle of the eye to the posterior edge of the hypural plate (MEHP). MEHP measurements were converted to fork length (FL) by using a conversion formula from male Fish Creek chum salmon carcasses measured in 1974: $(F L=1.21(M E H P)+32.8$; $\left.n=51 ; r^{2}=0.923 ; P<0.001\right)$. Annual sample sizes for a given stock varied from 6 to 86 scales. Years with no data included 1995, 1997, and 2001 for Fish Creek and 1980 for Quilcene River.

\section{Scale processing and scale measurements}

Scales were processed for age and growth determination according to Arnold (1951). The acetate impressions were scanned at $24 \times$ magnification and stored in JPEG file format at $300 \mathrm{dpi}$. The electronic images were then imported into the digitizing software program Image $\mathrm{Pro}^{2}$ with ringed structure macros developed by Media Cybernetics (Bethesda, MD). Scales were screened and those showing evidence of resorption or regeneration were not used in the growth analysis. Each scale was measured along a reference line drawn along the longest axis of the posterior portion of the scale from the center of the focus to the leading edge of the $9^{\text {th }}$ circulus (Sa), $21^{\text {st }}$ circulus (Sb), $1^{\text {st }}$ annulus ( $\mathrm{Sc}$ ), $2^{\text {nd }}$ annulus (S2), $3^{\text {rd }}$ annulus (S3), and to the edge of the scale (S4). We use the terms annulus and annuli in a restricted sense to mean those groups of circuli that represent growth from 1 year to the next.

Growth during specified time periods during the first year at sea was estimated from intercirculus spacings in the first ocean zone on the scale (Fukuwaka and Kaeriyama, 1997). We estimated and assumed that circuli formed at an approximately constant rate (1 circulus/7-10 days) on the basis of the total number of circuli in the first ocean zone and the length of the growing season (time of fry out-migration to the time of formation of the first marine annulus on the scale). Fish Creek chum salmon fry leave their native streams from March through May (Heinl, 2005) and form an average of 30 to 35 (mean=32) circuli during the first year at sea. Quilcene River chum salmon fry that are released into the Quilcene River from the hatchery in early May form an average of 33 to 40 circuli (mean=36) during the first year at sea. Although the Quilcene River chum salmon left freshwater later and had more circuli, this southern stock likely endured a longer growing season. $S a$ represented the first 2-3 months (63-90 days) at sea (April-May/June for Fish Creek and May-June/July for Quilcene River). $S b$ represented the next 3-4 months (84-120 days) at sea (June-August/Sept or July-Sept/ Oct for Fish Creek and July-Sept/Oct or Aug-Oct/Nov

\footnotetext{
2 Mention of trade names or commercial companies is for identification purposes only and does not imply endorsement by the National Marine Fisheries Service, NOAA.
}

for Quilcene River). $S c$ represented the remaining time through the end of the first growing season, before formation of the first winter annulus on the scale.

\section{Growth indice}

For each stock, saltwater growth $(S W)$ in body length $(\mathrm{mm})$ was back-calculated for the early juvenile $(S W 1 \mathrm{a})$, middle juvenile ( $S W 1 b)$, late juvenile $(S W 1 c), 1^{\text {st }}$ immature (SW2), $2^{\text {nd }}$ immature (SW3), and maturing (SW4) life stages by using the Fraser-Lee back-calculation equation (Lee, 1920). With this method, fish length is assumed to be directly proportional to scale radius (Dahl, 1909; Kaeriyama, 1998). The equation was given as

$$
\bar{L}_{t, i}=40+\left(\bar{L}_{t, t o t a l}-40\right) \cdot\left(\bar{S}_{t, i} / \bar{S}_{t, t o t a l}\right),
$$

where $t=$ year;

$40=$ length of the fish at the time of scale formation $(\mathrm{mm})$;

$\bar{L}_{t, i}=$ mean total body length at stage $i$;

$\bar{L}_{t, t o t a l}=$ mean total body length of the carcass samples;

$\bar{S}_{t, i}=$ mean radius from the focus to the mark on the reference line on the scale; and

$\bar{S}_{t, \text { total }}=$ mean total radius of the scale.

We set the intercept to $40 \mathrm{~mm}$, the length at the time of formation of the scale for chum salmon (Kobayashi, 1961; Helle, 1979). Finally, $S W$ indices were calculated as the differences in the back-calculated lengths $(L)$ for each life stage: early juvenile $(S W 1 a=L a)$, middle juvenile $(S W 1 b=L b-L a)$, late juvenile $(S W 1 c=L c-L b)$, $1^{\text {st }}$ immature year $(S W 2=L 2-L c), 2^{\text {nd }}$ immature year $(S W 3=L 3-L 2)$, and maturing $(S W 4=L 4-L 3)$.

\section{Salmon abundance indices}

Chum and pink salmon abundance indices for early juvenile (SW1a), middle juvenile (SW1b), late juvenile (SW1c), $1^{\text {st }}$ immature (SW2), $2^{\text {nd }}$ immature (SW3), and maturing (SW4) stages were back-calculated from the numbers of pink and chum salmon returns (harvest and escapement) of North America by management region, time series of age composition of chum salmon, and marine mortality schedules for pink and chum salmon.

The pink and chum salmon abundance indices $N$ for year $t$ were estimated with the following equation:

$$
N_{t}=\Sigma\left(p_{a, t+a} R_{a, t+a} \frac{1}{\Pi S_{a}}\right),
$$

where $p=$ the proportion of chum salmon of each age class for samples taken in-river;

$a=$ age class;

$R=$ returns (catch and escapement); and

$\Pi S=$ the product of daily survival rates from the middle of the life stage to the end of life.

Abundance indices were based on estimates of returns (harvest and escapement) of pink and chum salmon from Ruggerone et al. (2010). For each life 
stage, combined and separate indices for chum and pink salmon abundance were calculated for WA and southern BC (SBC), northern BC (NBC), southern and northern British Columbia (BC), southeast Alaska and Yakutat (SE), SE to the Alaska Peninsula (AP) (SE$\mathrm{AP}), \mathrm{BC}$ through AP (BC-AP) and Asia (AS) owing to overlap in the distribution and diets of juvenile and adult pink and chum salmon (Fig. 1) (Orsi et al. ${ }^{3}$; Davis et al. $\left.{ }^{4}, 2009\right)$. Chum salmon abundance indices were calculated by age $(0.0,0.1,0.2,0.3)$ to match each age during the growth period (SW1, SW2, SW3, SW4). For this study, SW1a, SW1b, and SW1c were related to age 0.0 pink and chum salmon abundances, SW2 was related to age 0.1 pink and chum salmon abundances, SW3 was related to age 0.1 pink salmon and age 0.2 chum salmon abundances, and SW4 was related to age 0.1 pink salmon and age 0.3 chum salmon abundances. Three chum and pink salmon abundance indices were calculated for SW1 growth during age-0.0, the first year at sea. Maturing pink salmon were combined with the immature and maturing chum salmon because of spatial and dietary overlaps (Davis et al.4).

Each juvenile growth variable was related to three salmon abundance indices (chum salmon, pink salmon, and chum and pink salmon combined) from various regional groupings. For Fish Creek chum salmon, SW1a was related to $\mathrm{SE}$ salmon abundance indices (3 indices), SW1b was related to SE and BC-SE salmon abundance (6 indices), and SW1c was related to SE, BC-SE, SE-AP salmon abundance (9 indices). For Quilcene River chum salmon, SW1a was related to SBC salmon abundance (3 indices), SW1b was related to $\mathrm{BC}$ and BC-SE salmon abundance (6 indices), and SW1c was related to $\mathrm{SE}, \mathrm{BC}-\mathrm{SE}, \mathrm{SE}-\mathrm{AP}$ salmon abundance (9 indices). For the immature and maturing stages, chum salmon growth was related to two salmon abundance indices (chum salmon and chum and pink salmon combined) from various regional groupings. For Fish creek chum salmon, SW2, SW3, and SW4 were related to SE, BC-SE, SE-AP, BC-AP, BC-AS, and AS (12 indices). For Quilcene River chum salmon, SW2, SW3, and SW4 were related to $\mathrm{BC}, \mathrm{BC}-\mathrm{SE}, \mathrm{SE}-\mathrm{AP}, \mathrm{BC}-\mathrm{AP}, \mathrm{BC}-\mathrm{AS}$, and AS (12 indices).

Age composition for chum salmon in Alaska and Asia was assumed to be well characterized by the time series of age composition from the Fish Creek stock, whereas the age composition for the BC stocks was assumed to be characterized by age composition from the Quilcene River stock.

\footnotetext{
${ }^{3}$ Orsi, J., A. Wertheimer, M. Sturdevant, E. Fergusson, and B. Wing. 2009. Insights from a 12-year biophysical time series of juvenile Pacific Salmon in southeast Alaska: the Southeast Alaska Coastal Monitoring Project (SECM). NOAA Alaska Fisheries Science Center AFSC Q. Res. Rep., 8 p. [Available at website.]

${ }^{4}$ Davis, N. D., K. W. Myers, and Y. Ishida. 1998. Bering Sea salmon diet overlap in fall 2002 and potential for interactions among salmon. North Pacific Anadromous Fish Commission (NPAFC) Doc. 779, $30 \mathrm{p}$.
}

Marine mortality rates were calculated from fry to maturity. Marine mortality rates were approximately 97\% for chum and pink salmon (Kaeriyama, 1998). Approximately $70 \%$ of the total mortality occurs within the first 40 days at sea (Parker, 1968) and pink salmon experience a mortality of $2-4 \%$ (we used $3 \%$ ) mortality per day for the first 40 days and $0.4-0.8 \% / d$ (we used $0.6 \% / d$ ) thereafter (Parker, 1968). These daily mortality rates were used to develop a survival rate schedule by life stage for pink and chum salmon. The products of the daily survival rates were used to expand returns to reflect abundance during the middle of each life stage in our study.

\section{Climate indices}

The six climate indices used in this study were mean late spring (May-June) wind speed $(\mathrm{m} / \mathrm{s})$, mean fall (Sept-Oct) wind speed $(\mathrm{m} / \mathrm{s})$, deepest winter (Dec-Feb) mixed layer depth $(\mathrm{m})$, spring transition index (day of year), mean summer/fall (July-Oct) SST $\left({ }^{\circ} \mathrm{C}\right)$, and the winter (Dec-Feb) Pacific Decadal Oscillation (PDO) index.

Wind speed index Surface wind speed data were accessed from the website of the NOAA Fisheries Southwest Fisheries Science Center's Environmental Research Division (website, accessed Sept 2009). Indices were derived from data sets of atmospheric pressure fields at 6-hour intervals from the Fleet Numerical Meteorology and Oceanography Center. The spring wind (WS) index was calculated as the values for April 16 or 17 at Dixon Entrance off southern SE Alaska $\left(56.5^{\circ} \mathrm{N}\right.$, $\left.134.5^{\circ} \mathrm{W}\right)$. The fall wind (WF) index was calculated as the average of the September and October monthly wind index values at the surface east of Kodiak Island $\left(58.5^{\circ} \mathrm{N}, 150.0^{\circ} \mathrm{W}\right)$.

Mixed layer depth index A mixed layer depth (MLD) index for winter was available for the mouth of Resurrection Bay $\left(60^{\circ} \mathrm{N}, 149^{\circ} \mathrm{W}\right)$ in the northern GOA (Sarkar, 2007). The Freeland et al. (1997) algorithm was used to calculate the deepest winter MLD (m).

Spring upwelling transition index The spring transition index (STI) represents the timing (day of year) of the transition from downwelling to upwelling off the coast of WA and OR (Logerwell et al., 2003). The STI values ranged from 48 in 1985 to 161 in 1993. The transition occurs between March and June.

Upwelling magnitude index The monthly magnitude of upwelling $\left(\mathrm{m}^{3} \cdot \mathrm{s}^{-1} \cdot 100 \mathrm{~m}^{-1}\right.$ of coastline) off WA was accessed from NOAA's Pacific Fisheries Environmental Laboratory website (website, accessed Sept 2008). The location of the upwelling index (UI) was 23 nautical miles (nmi) south and $13 \mathrm{nmi}$ west of Cape Flattery at the tip of the Olympic peninsula off the WA coast $\left(125^{\circ} \mathrm{W}\right.$ and $\left.48^{\circ} \mathrm{N}\right)$. A spring UI was calculated as the sum of the May and June indices. 
Sea temperature Sea temperature data for the eastern North Pacific Ocean were available from NOAA's Earth System Research Laboratory's Physical Sciences Division website (website, accessed April 2012). The NCEP/ NCAR re-analyzed SST data set was used (Kalnay et al., 1996) to derive average monthly SST for a region east of $157.5^{\circ} \mathrm{W}$ and north of $52.4^{\circ} \mathrm{N}$. Averages were computed for 3 grids of equal area $\left(52.4^{\circ} \mathrm{N}-48.6^{\circ} \mathrm{N} \times 148.1^{\circ} \mathrm{W}-\right.$ $157.5^{\circ} \mathrm{W}, \quad 52.4^{\circ} \mathrm{N}-48.6^{\circ} \mathrm{N} \times 148.1^{\circ} \mathrm{W}-138.7^{\circ} \mathrm{W}$, and $\left.58.1^{\circ} \mathrm{N}-52.4^{\circ} \mathrm{N} \times 148.1^{\circ} \mathrm{W}-138.7^{\circ} \mathrm{W}\right)$ and the 3 areas were then averaged for each year from 1972 to 2004 . An index was constructed from the average of the monthly SST from July 1 through Oct 31 to encompass the warmest months of the year.

Pacific Decadal Oscillation index The PDO was calculated as the leading principle component of the Reynolds optimally interpolated monthly SST anomalies poleward from $20^{\circ} \mathrm{N}$ (Zhang et al., 1997). Data were available from the website of Steven Hare and Nathan Mantua at the University of Washington Joint Institute for the Study of the Atmosphere and Ocean (Hare and Mantua, 2000). The mean winter PDO was calculated as the average of the monthly Dec (in year $t-1$ ), Jan (in year $t$ ), and Feb (in year $t$ ) PDO values. The correlation coefficient between the winter PDO and the summer SST time series was not statistically significant.

\section{Analytical techniques}

Scatter and line plots were used to assess temporal variation in the average length at maturity and growth during each life stage by stock. For the models, each time series was scaled and centered by subtracting the mean and dividing by the standard deviation. This allowed for interpretation of the model coefficients as the number of standard deviations of change in growth for each 1 standard deviation change in the predictor variable. For example, a coefficient of $-0.500(0.500)$ indicates a $50 \%$ decrease (increase) in 1 standard deviation of the dependent variable (growth) with an increase of 1 standard deviation in the predictor variable (abundance, length, or climate).

We used a transfer function-noise model introduced for fisheries by Noakes et al. (1987) to explain variation in growth. The growth dynamic model was a regression equation with an error correction equation. The regression equation based on a generalized least squares (GLS) method was used to describe growth as a function of chum and pink salmon abundance and body length at the start of the growing season. The error correction model was used to capture additional variation in growth due to multicollinearity among climate and salmon production. The GLS regression equation was given as

$$
\begin{aligned}
S W_{i, t} & =\beta_{1}\left(\text { Abundance }_{t}\right)+\beta_{2}\left(\text { Abundance }_{t}\right)^{2} \\
& +\beta_{3} \text { Length }_{t-1}+\varepsilon_{t},
\end{aligned}
$$

where $t=$ year or season;

$S W_{i, t}=$ growth variable at stage $i$ in year $t ;$ stage $i=1 \mathrm{a}, 1 \mathrm{~b}, 1 \mathrm{c}, 2,3,4$;

Abundance $_{t}=$ a chum and/or pink salmon abundance index in year $t$

Length $_{t-1}=$ the length of the fish at the end of the previous growing season;

$\beta=$ the coefficient; and

$\varepsilon_{t}=$ the residuals.

The process encompasses contemporaneous and serially correlated sample, observation, and model specification error. To test for domeshaped or asymptotic relationships between growth and abundance and climate, we added variables for the square of the abundance. Degrees of freedom were calculated for the GLS model $(n-k)$ from the number of observations in a time series $(n)$ and the number of coefficients in model $(k)$.

The error correction equation (Eq. 4) was used to extract signal from the noisy residuals from the regression equation (Eq. 3). A vector autoregression (VAR) equation was used to relate contemporaneous values of the regression model residuals with lagged values of the regression model residuals and lagged values of climate indices. In a system of two equations, the single VAR equation for two variables was given as

$$
\begin{gathered}
\varepsilon_{t}=B_{1, \varepsilon} \varepsilon_{t-1+\ldots+} B_{i, \varepsilon} \varepsilon_{t-j+\ldots}+B_{p, \varepsilon} \varepsilon_{t-p} \\
+B_{1, x} X_{t-1}+\ldots+B_{i, x} X_{t-j}+B_{p, x} X_{t-p}+e_{t},
\end{gathered}
$$

where $X_{t}=$ a climate index;

$\varepsilon_{t}=$ a vector time series of the growth dynamic equation residuals for the two equations;

$B_{i, j}=$ coefficients to be estimated;

$X_{t}=$ a vector of climate indices in time $t$;

$p=$ the maximal lag length; and

$e_{t}=$ the residuals.

For the equation, the maximum likelihood estimator for the matrix coefficient $B$ was $B=Y^{\prime} Z^{\prime}\left(Z^{\prime} Z\right)^{-1}$ where $Z$ was a matrix composed of the elements of $\varepsilon$ and $X$. Because the estimated coefficients of the VAR were conditional on the residuals of the growth model and because the estimated coefficients of the growth model were inefficient when serial correlation was present, it was necessary to iterate with equations 3 and 4 until the coefficient estimates of the both equations converged to stable values. The degree of freedom for the GLS and VAR integrated model were $(n \cdot \mathrm{m}-k-p \cdot \mathrm{m})$, where $p$ was the number of lag years and $m$ was the number of time series in the VAR equation. We limited the maximum lag to 4 years to account for the possible direct or indirect effect of generation cycles on growth.

To test the performance of the models, data were partitioned into two sets (in-sample set and reserved observations set). The insample set was used for coefficient estimation and model specification. The reserved observations set was used for model validation. The insample set consisted of the first approximately $80 \%$ of the observations. The remaining $20 \%$ of the observations, reserved observations, were reserved to generate outofsample predictions by using coefficients obtained for the insample model. Various software programs were used in the exploration of the time series, the 


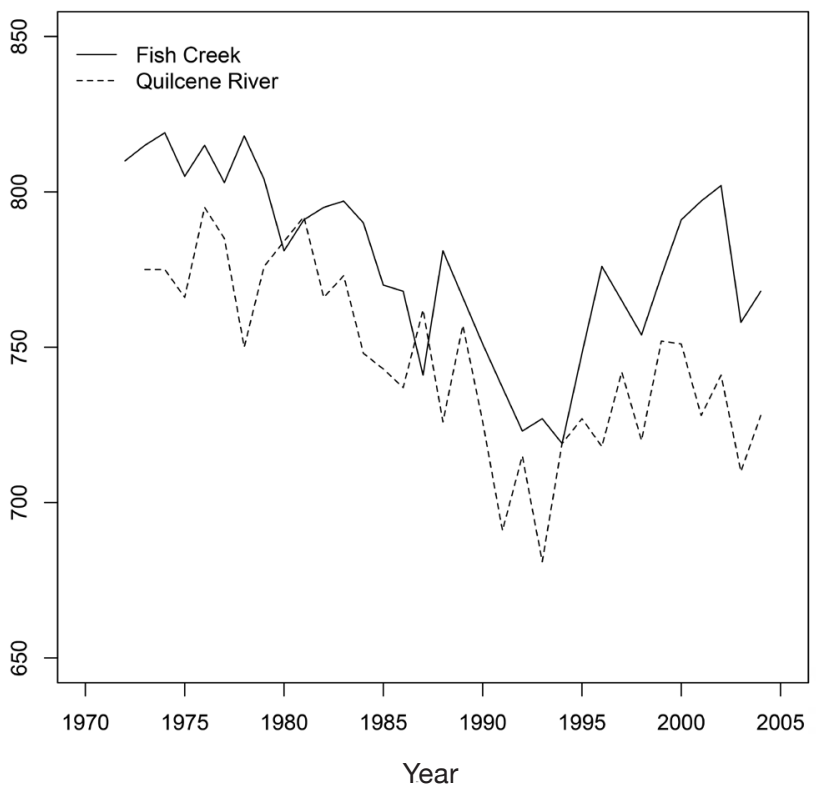

Figure 2

Average body length of age-0.3 male chum salmon (Oncorhynchus keta) carcasses at Fish Creek, Alaska from 1972 to 2007 and Quilcene River, Washington, from 1973 to 2007.

models and for determining model performance (Lehmann, 1959).

To compare our findings with other observational data, we examined the mean body length of juvenile chum salmon and the surface trawl catch of juvenile pink and chum salmon from continental shelf waters off Icy Point in the GOA from 1997 to 2011 (courtesy of the SE Coastal Monitoring Program, Alaska Fisheries Sciences Center, Juneau, Alaska).

\section{Results}

\section{Trends in body size and growth}

Trends in annual mean body length at maturity for age-0.3 male chum salmon were similar for the Fish Creek and Quilcene River stocks but on different scales (Fig. 2). From the 1970s to the early $1990 \mathrm{~s}$, mean length decreased by about 11.6\% (99 mm) for Fish Creek chum salmon (from 815 to $720 \mathrm{~mm}$ ) and by $8.6 \%(60 \mathrm{~mm}$ ) for Quilcene River chum salmon (from 780 to 720 $\mathrm{mm}$ ). The decline was followed by an increase in body length in both populations, but the increase from the early 1990 s to 2000 was much larger for Fish Creek chum salmon (9.7\%) than for Quilcene River chum salmon (2.8\%). How-

GLS regression modeling, and VAR modeling (Simetar, Simetar Inc., College Station, TX; Excel 2013, Microsoft Corp., Redmond, WA).

Model specification and selection was based on a Bonferonni correction factor and the lowest Schwarz information criterion (SIC) for each of the 12 growth variables. The SIC was applied to add a penalty for the number of predictor variables in the model. Abundance indices were added separately to GLS models because of multicollinearity. A Bonferroni correction factor was applied to the $P$-value of the coefficients for abundance to account for the number of abundance indices used in each model ( $\alpha=0.05$ /number of possible predictors variables). The final GLS/VAR models were tested for heteroscedasticity of the residuals (Goldfeld-Quandt test, absolute residuals vs. fitted values plot), normality of the residuals (qq plots, studentized residuals vs. fitted values, and Shapiro test), and serial correlation of the residuals (autocorrelation test). Selection of the final GLS model and a comparison of the GLS and the GLS/ VAR model were based on the SIC.

To test model performance, an $F$-test was used to determine whether the mean squared error was significantly greater for reserved observations and estimates than for in-sample observations and estimates. If the test statistic exceeded the critical value, model performance was judged to have deteriorated over the reserved observations, indicative of model misspecification. Lehmann's correlation was used to determine whether the mean squared error was reduced by integrating the climate and residuals using the VAR ever, neither stock had regained body lengths observed in the $1970 \mathrm{~s}$.

Trends in SW2 and SW3 incurred offshore were similar for Fish Creek and Quilcene River chum salmon (Fig. 3). SW2 and SW3 declined from the mid-1970s to the mid-1990s and increased from the mid-1990s to the mid-2000s. Declines in growth from the mid-1970s to the mid-1990s also occurred in SW1a, SW1b, and SW4 for Fish Creek chum salmon but remained low from the mid-1990s to the mid-2000s. No trends were observed in SW1c for Fish Creek chum salmon and in SW1a, SW1b, SW1c, and SW4 for Quilcene River chum salmon.

\section{Growth models}

Growth was linearly and inversely related to both chum and pink salmon abundance indices. Growth was inversely related to chum or pink salmon abundance (or both abundances) for SW1b, SW2, SW3, and SW4 for chum salmon from Fish Creek and for SW2, SW3, and SW4 for chum salmon from Quilcene River. Only one growth variable was more strongly correlated with climate than chum and pink salmon abundance. SW1c for Fish Creek chum salmon was inversely related to the magnitude of fall wind speed in the northern GOA (Table 2).

\section{Models for Fish Creek chum salmon}

SW1b was significantly and negatively correlated with the estimated abundance of juvenile pink salmon from 

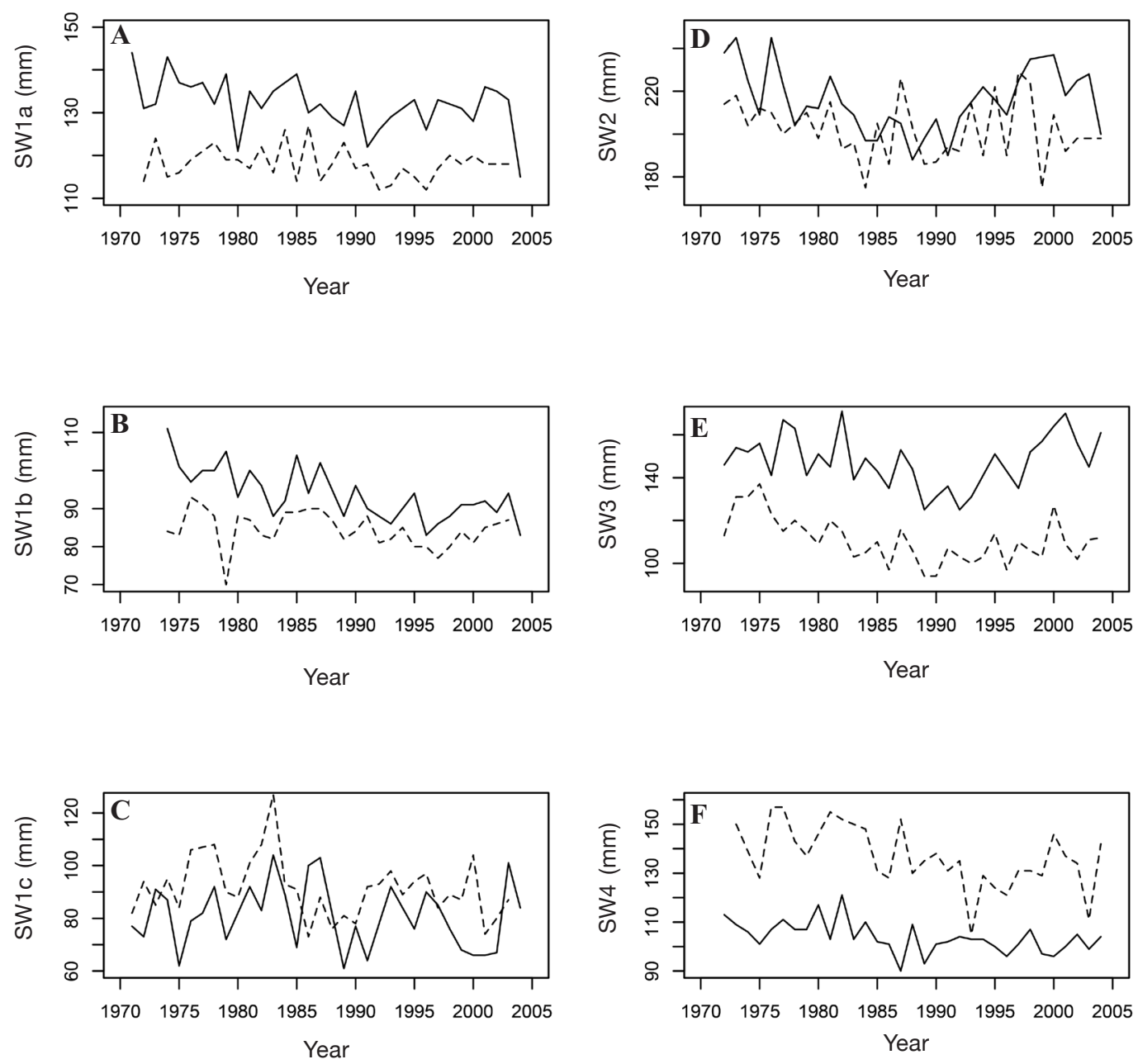

Figure 3

Average ocean growth ( $\mathrm{mm}$ ) of age-0.3 male chum salmon (Oncorhynchus keta) from Fish Creek (FC) Alaska and Quilcene River (QR), Washington. Time series data include (A) early juvenile growth SW1a (FC: 1971-2004 and QR:1972-2004), (B) middle juvenile growth SW1b (FC: 1974-2004; QR: 1974-2003), (C) late juvenile growth SW1c (FC: 1971-2004, (D) $1^{\text {st }}$ immature year growth SW2 (FC: 1972-2004 and QR: 1972-2004), (E) $2^{\text {nd }}$ immature year growth SW3 (FC: 1972-2004 and QR: 1972-2004), and (F) maturing growth SW4 (FC: 1972-2004 and QR: 1973-2004). Solid lines represent FC and dashed lines represent QR.

SE Alaska to the AP management-region harvests and was positively related to length at the start of the growing season (La) (Table 2). Seventy percent of the variation in SW1b was explained by La and pink salmon abundance $\left(r^{2}=0.70 ; P<0.001\right)$.

SW1c was negatively correlated with the velocity of fall winds, but not correlated with pink and chum salmon abundance. Fall winds explained $39 \%$ of the variation in SW1c.

SW2 was inversely related to the combined abundances of immature age- 0.1 chum salmon and maturing pink salmon on the basis of abundance data from $\mathrm{BC}$ to the south of the AP (Table 2). The SIC was further reduced by including lagged values of SST, PDO, and growth in the error correction model. SW2 was positively correlated with summer SST 2 years earlier and negatively correlated with the winter PDO 4 years earlier. The variables in the GLS/VAR model explained an additional $27 \%$ of the variation in SW2 in comparison with the GLS model. Performance measures indicated no change in the coefficients of variation when the error correction term was included in the SW2 model.

SW3 was negatively correlated with the abundance of immature age-0.2 chum salmon from BC to SE Alaska and maturing pink salmon from BC to SE Alaska (Table 2). Abundance explained $35 \%$ of the variation in SW3. Growth was also significantly and negatively cor- 


\section{Table 2}

Insample generalized least squares (GLS) models and the integrated GLS and vector autoregression error correction models for the growth of age0.3 male chum salmon (Oncorhynchus keta) from Fish Creek, Alaska. Growth indices include middle juvenile growth (SW1b), late juvenile growth (SW1c), $1^{\text {st }}$ immature year growth (SW2), $2^{\text {nd }}$ immature year growth (SW3), and maturing growth (SW4). Length indices include early juvenile length (La) and total juvenile length (L1). $\mathrm{J}_{\mathrm{SE}-\mathrm{APt}, \text { Pink,t }}=$ juvenile pink salmon abundances from southeast Alaska to the Alaska Peninsula. $\mathrm{I}_{\mathrm{SEAP}, \mathrm{t}}=$ immature chum salmon and maturing pink salmon from southeast Alaska to the Alaska Peninsula. $\mathrm{I}_{\mathrm{BC}-\mathrm{SE}, \mathrm{t}}=$ immature chum salmon and maturing pink salmon from British Columbia to southeast Alaska. $\mathrm{M}_{\mathrm{AS} \text {,Chum,t }}=$ maturing chum salmon from Asia. WF=fall wind speed. SST=sea surface temperature. PDO=the Pacific Decadal Oscillation index. Model statistics included coefficient estimates (coeff.), $P$-values of the coefficients ( $P$-value), the coefficient of determination $\left(r^{2}\right), P$ value of the $F$ statistic, coefficient of variation (CV), and Schwarz information criterion (SIC).

\begin{tabular}{|c|c|c|c|c|c|c|c|}
\hline \multicolumn{2}{|c|}{ Variables } & \multicolumn{6}{|c|}{ Model statistics } \\
\hline Response & Predictors & Coeff. & $P$-value & $r^{2}$ & $P$-value & $\mathrm{CV}$ & SIC \\
\hline SW1b & $\begin{array}{l}\mathrm{La}_{\mathrm{t}-1} \\
\mathrm{~J}_{\mathrm{SEAP}, \text { Pink,t }}\end{array}$ & $\begin{array}{r}0.618 \\
-0.538\end{array}$ & $\begin{array}{l}<0.001 \\
<0.001\end{array}$ & 0.70 & $<0.001$ & 0.039 & 165 \\
\hline SW1c & $\mathrm{WF}_{\mathrm{t}}$ & -0.571 & $<0.001$ & 0.39 & $<0.001$ & 0.111 & 205 \\
\hline SW2 & $\begin{array}{l}\mathrm{L} 1_{\mathrm{t}-1} \\
\mathrm{I}_{\mathrm{SEAP}, \mathrm{t}}\end{array}$ & $\begin{array}{r}-0.582 \\
0.741\end{array}$ & $\begin{array}{l}<0.001 \\
<0.001\end{array}$ & 0.50 & $<0.001$ & 0.049 & 218 \\
\hline SW2 & $\begin{array}{l}\mathrm{L}_{\mathrm{t}-1} \\
\mathrm{I}_{\mathrm{SEAP}, \mathrm{t}} \\
\mathrm{SST}_{\mathrm{t}-2} \\
\mathrm{PDO}_{\mathrm{t}-4}\end{array}$ & $\begin{array}{r}-0.582 \\
-0.741 \\
0.438 \\
-0.321\end{array}$ & $\begin{array}{r}<0.001 \\
<0.001 \\
<0.001 \\
0.001\end{array}$ & 0.77 & $<0.001$ & 0.031 & 193 \\
\hline SW3 & $\mathrm{I}_{\mathrm{BC}-\mathrm{SE}, \mathrm{t}}$ & -0.605 & 0.001 & 0.35 & 0.001 & 0.066 & 208 \\
\hline SW4 & $\mathrm{M}_{\mathrm{AS}, \mathrm{Chum}, \mathrm{t}}$ & 0.602 & 0.0016 & 0.34 & 0.002 & 0.052 & 178 \\
\hline SW4 & $\begin{array}{l}\mathrm{M}_{\mathrm{AS}, \mathrm{t}, \mathrm{Chum}, \mathrm{t}} \\
\mathrm{SST}_{\mathrm{t}-1} \\
\mathrm{PDO}_{\mathrm{t}-3}\end{array}$ & $\begin{array}{r}0.556 \\
0.388 \\
-0.302\end{array}$ & 0.0016 & 0.46 & $<0.0001$ & 0.047 & 175 \\
\hline
\end{tabular}

related with SST, but the SIC was lower than for the model with abundance.

SW4 was most strongly and inversely correlated with the abundance of maturing chum salmon from Asia $\left(r^{2}=0.34 ; P=0.002\right)$. SW4 was not significantly related to other abundance or with SST and PDO during the year of growth. The SST at a 1 year lag and the $\mathrm{PDO}$ at a 3 year lag explained additional variation in SW4 and were both significant in the VAR model $(r$ $2=0.46 ; P<0.001)$.

\section{Quilcene River chum salmon models}

Quilcene River chum salmon growth was inversely related to chum and pink salmon abundance during immature and maturing life stages, but not during the juvenile stage (Table 3). All sets of residuals passed the tests for normality, homoscedasticity, and serial correlation.

SW2 was inversely correlated with the abundance of immature age-0.1 chum salmon from Asia. Abundance explained $35 \%$ of the variability in growth in the GLS model $\left(r^{2}=0.35 ; P<0.001\right)$ (Table 3$)$.

SW3 was inversely correlated with the abundance of maturing age-0.1 pink salmon and immature age0.2 chum salmon from $\mathrm{BC}$ to southern $\mathrm{AP}\left(r^{2}=0.52\right.$;
$P<0.001$ ) (Table 3). The GLS/VAR model explained an additional $21 \%$ in growth $\left(r^{2}=0.73 ; P<0.001\right)$ and reduced the SIC. Similar to the $1^{\text {st }}$ immature year growth models for Fish Creek, growth was positively correlated with SST and negatively correlated with the PDO at a 2-year lag.

SW4 was negatively correlated with the abundance of maturing chum salmon from Asia $\left(r^{2}=0.52 ; P<0.001\right)$ (Table 3). Maturing growth was not correlated with the climate indices in this study.

\section{Model validation}

For the reserved observations, the growth models did not perform well in the model validations (Tables 4 and 5 ). Positive $r^{2}$ values occurred for SW1b and SW4 Fish Creek and SW4 Quilcene River models. Negative $r^{2}$ values indicated that the mean of the growth time series performed better in model validation, when model predictions were tested against $20 \%$ of the data that were not used for model specification, than did the fitted values for the juvenile and immature models. Significant model deterioration occurred for the SW2 GLS and GLS/VAR and SW3 GLS models for Fish Creek and for the SW2 GLS and SW3 GLS/VAR models for Quilcene River as indicated by the $F$-statistic for model dete- 
Table 3

Insample generalized least squares (GLS) models and the integrated GLS and vector autoregression error correction models for the growth of age0.3 male chum salmon (Oncorhynchus keta) from Quilcene River, Washington. Growth indices included $1^{\text {st }}$ immature year, $2^{\text {nd }}$ immature year (SW3), and maturing (SW4) life stages. SST=sea surface temperature. PDO=the Pacific decadal oscillation index. $\mathrm{I}_{\mathrm{AS}, \text { Chum,t }}=$ immature Asian chum salmon. $\mathrm{I}_{\mathrm{BC}-\mathrm{SE}, \mathrm{t}}=$ immature chum and pink salmon abundance from British Columbia to southeast Alaska. $\mathrm{M}_{\mathrm{AS} \text {,Chum,t }}=$ maturing chum salmon abundances from Asia. Model statistics included coefficient estimates (coeff.), $P$-values of the coefficients ( $P$-value), the coefficient of determination $\left(r^{2}\right), P$-value of the $F$-statistic, coefficient of variation (CV), and Schwarz information criterion (SIC).

\begin{tabular}{|c|c|c|c|c|c|c|c|}
\hline \multicolumn{2}{|c|}{ Variables } & \multicolumn{6}{|c|}{ Model statistics } \\
\hline Response & Predictors & Coeff. & $P$-value & $r^{2}$ & $P$-value & $\mathrm{CV}$ & $\mathrm{SIC}$ \\
\hline SW2 & $\mathrm{I}_{\mathrm{AS}, \mathrm{Chum}, \mathrm{t}}$ & -0.562 & $<0.001$ & 0.35 & $<0.001$ & 0.054 & 214 \\
\hline SW3 & $\mathrm{I}_{\mathrm{BC}-\mathrm{SE}, \mathrm{t}}$ & -0.797 & $<0.001$ & 0.52 & $<0.001$ & 0.070 & 196 \\
\hline \multirow[t]{3}{*}{ SW3 } & $\mathrm{I}_{\mathrm{BC}-\mathrm{SE}, \mathrm{t}}$ & -0.835 & $<0.001$ & 0.73 & $<0.001$ & 0.052 & 183 \\
\hline & $\mathrm{SST}_{\mathrm{t}-2}$ & 0.450 & $<0.001$ & & & & \\
\hline & $\mathrm{PDO}_{\mathrm{t}-2}$ & -0.434 & $<0.001$ & & & & \\
\hline SW4 & $\mathrm{M}_{\mathrm{AS}, \text { Chum, } \mathrm{t}}$ & 0.718 & $<0.001$ & 0.52 & $<0.0001$ & 0.063 & 202 \\
\hline
\end{tabular}

rioration ( $F$-det.). The growth model for maturing fish did not deteriorate, but the coefficient of determination was close to zero.

According to the results of the Lehmann's correlation test (Table 6), the mean squared errors were significantly reduced for both insample regression equations when integrating the error correction equation. However, the mean squared error was not significantly reduced for any model when applied to the reserved observations.

From the SECM survey, at the station with the highest annual catch of juvenile pink salmon and chum salmon (>250 fish), we found an inverse relationship between the interannual mean length of chum salmon and catch of juvenile pink and juvenile chum salmon.

\section{Discussion}

Our study advances the understanding of potential factors influencing marine growth of chum salmon in the North Pacific Ocean. With this study, we have contributed two more chum salmon populations, 1 from the southeast Alaska and 1 from Washington state, to an

\section{Table 4}

Validation statistics based on the application of the growth models for age- 0.3 male chum salmon (Oncorhynchus keta) from Fish Creek, Alaska to the reserved observations. GLS=the generalized least squares regression model. Growth indices included middle juvenile (SW1b), late juvenile (SW1c), $1^{\text {st }}$ immature year, $2^{\text {nd }}$ immature year (SW3), and maturing (SW4) life stages. GLS/VAR was the GLS and vector autoregression-integrated model. Statistics include sample size $(n)$, coefficient of variation $(\mathrm{CV})$, coefficient of determination $\left(r^{2}\right), F$-statistic, $P$-value of the $F$-statistic, $F$-statistic of model deterioration ( $F$-det.), $P$-value of $F$-det. ( $P$-det.), and the Schwarz's information criterion (SIC). Negative $r^{2}$ values and associated $F$ and $P$ values were not shown for the SW1c, SW2, SW3 and SW4 GLS models.

\begin{tabular}{|c|c|c|c|c|c|c|c|}
\hline & SW1b & SW1c & SW2 & SW2 & SW3 & SW4 & SW4 \\
\hline & GLS & GLS & GLS & GLS/VAR & GLS & GLS & GLS/VAR \\
\hline$n$ & 6 & 7 & 7 & 7 & 7 & 7 & 7 \\
\hline $\mathrm{CV}$ & 0.05 & 0.14 & 0.07 & 0.07 & 0.12 & 0.05 & 0.04 \\
\hline$r^{2}$ & 0.25 & & & & & & 0.27 \\
\hline$F$ & 1.01 & & & & & & 1.32 \\
\hline$P$ & 0.44 & & & & & & 0.36 \\
\hline$F$-det. & 1.47 & 1.41 & 2.38 & 6.10 & 3.64 & 0.77 & 0.69 \\
\hline$P$-det. & 0.23 & 0.25 & 0.05 & $<0.0001$ & 0.008 & 0.61 & 0.68 \\
\hline SIC & 34 & 51 & 56 & 63 & 58 & 39 & 41 \\
\hline
\end{tabular}




\section{Table 5}

Validation statistics based on the application of the growth models for age-0.3 male chum salmon ( $\mathrm{On}$ corhynchus keta) from Quilcene River, Washington to the reserved observations. GLS was the generalized least squares regression model. Growth indices included $1^{\text {st }}$ immature year (SW2), $2^{\text {nd }}$ immature year (SW3), and maturing (SW4) life stages. GLS/VAR was the GLS and vector autoregression-integrated model. Statistics include sample size $(n)$, coefficient of variation $(\mathrm{CV})$, coefficient of determination $\left(r^{2}\right), F$-statistic, $P$-value of the $F$-statistic, $F$-statistic of model deterioration ( $F$ det.), $P$-value of $F$ det. ( $P$-det.), and the Schwarz's information criterion (SIC). Negative $r^{2}$ values and associated $F$ and $P$ values were not shown for the SW2, SW3 and SW4 models.

\begin{tabular}{lllll}
\hline & SW2 & SW3 & SW3 & SW4 \\
\hline & GLS & GLS & GLS/VAR & GLS \\
$n$ & 7 & 7 & 7 & 6 \\
CV & 0.09 & 0.07 & 0.11 & 0.09 \\
$r^{2}$ & & & & 0.06 \\
$F$ & & & & 0.18 \\
$P$ & & & & 0.98 \\
$F$-det. & 2.52 & 1.14 & 4.13 & 1.79 \\
$P$-det. & 0.04 & 0.37 & 0.001 & 0.14 \\
SIC & 57 & 47 & 56 & 44 \\
& & & & \\
\hline
\end{tabular}

increasing body of growth studies on chum salmon populations from southcentral Alaska (Helle, 1979), western Alaska (Agler et al., 2013), Russia (Zavolokin et al., 2009), Japan (Kaeriyama et al., 2007), and Korea (Seo et al., 2006). Contrary to growth in the Asian populations, juvenile and maturing growth did not increase in the mid-1990s, indicating that productivity on the North American continental shelf remained relatively lower than that in the western Pacific Ocean. In addition, we back-calculated indices of chum and pink salmon abundance using harvest data, age composition, and mortality schedules; therefore, this index was more likely to accurately represent the actual abundance of chum salmon than estimates based on harvest alone. We found that size of the adult chum salmon was primarily related to growth in oceanic waters during the immature life stage on the basis of data from the early 1970 s to the mid-2000s and that immature growth was related to population abundance and to climate in prior years. Further research needs to focus on identifying and better understanding factors influencing immature growth in order to allow for more accurate predictions of size-at-maturity for returning chum salmon in a given year.

\section{Trends in size and growth}

Size at maturity was essential for determining fecundity, breeding success, and survival of progeny in salmon

\section{Table 6}

Lehmann's correlation coefficients to test the difference among the mean square errors of the growth models for age-0.3 male chum salmon (Oncorhynchus keta) from Fish Creek and the Quilcene River. Growth indices included $1^{\text {st }}$ immature year growth (SW2) and $2^{\text {nd }}$ immature year growth (SW3). GLS=the generalized least squares regression model. GLS/VAR=the GLS and vector autoregression-integrated model. Models were not statistically significant at a $5 \%$ level of significance.

\begin{tabular}{lccc}
\hline & \multicolumn{2}{c}{ Stock and life stage } \\
\cline { 3 - 4 } & & Fish Creek & Quilcene River \\
& & SW2 & SW3 \\
\hline Sample method & & GLS & GLS \\
Insample & GLS/VAR & 0.44 & 0.41 \\
Outsample & GLS/VAR & -0.08 & -0.50 \\
& & & \\
\hline
\end{tabular}

(Helle, 1979, 1989; Schroder, 1982). Therefore, it was important to understand factors influencing growth. Largebodied female salmon can dig deeper redds (van de Berghe and Gross, 1984), produce more eggs (Helle, 1989), produce larger eggs and fry (Koski, 1975), and have progeny with higher survival probability (Helle, $1979 ; 1989)$. Larger males are more aggressive and are more successful in competing for a mate than smaller males (Schroder, 1982). In the ocean, larger salmon consume more prey, more energy-rich prey, and more diverse prey than smaller salmon (Davis et al., 2009) and therefore have a competitive advantage for larger fish. Because a growth advantage once gained has a high likelihood of being maintained throughout the life of a fish, these factors highlight the significance of understanding the impacts of climate and population abundance on the marine growth and ultimately on the size at maturity of salmon.

In this study, the temporal trends in the body size at maturity of chum salmon from the two stocks from the early 1970 s to early 1990 s were similar to decreases in early juvenile, middle juvenile, immature, and maturing growth for Fish Creek chum salmon and to decreases in the immature and maturing growth for Quilcene River chum salmon. Our results are comparable to observed declines in body size of Hokkaido chum salmon in the mid-1980s that were linked to reduced growth during the $2^{\text {nd }}$ immature and maturing stages for years 1970-1994 (Kaeriyama, 1998). Similarly, the reduction in the adult (mature) body size of chum salmon from the Anadyr River in Russia during the mid-1980s was linked to reduced growth in the immature and maturing stages (Zavolokin et al., 2009). Although the general trends in size at maturity from the 1970 s to the 1990s were similar for different populations around the Pacific Ocean, the changes in adult size were linked to different developmental stages, namely the imma- 
ture and maturing life stages in the western Pacific and the juvenile, immature, and maturing life stages in the eastern Pacific. From the mid-1990s to the mid2000 s, increases in body size of adult chum salmon in our study were related to increases in growth during the immature life stage in offshore waters.

Juvenile and maturing growth of chum salmon from the two populations in our study did not recover from the size reductions of chum salmon from the early 1970 s to the early 1990s. Conversely, juvenile chum salmon released from Japan into the Sea of Okhotsk had lower growth from the late 1960s to the mid-1980s and higher growth from the mid-1980s to the mid-1990s, possibly because of reduced ice cover and warmer sea temperatures during summer and fall (Kaeriyama et al., 2007). Farther north in Russia, juvenile growth of chum salmon departing the Anadyr River was relatively stable from the early 1960s to the late 2000s, but slightly higher in the late $1990 \mathrm{~s}$ (Zavolokin et al., 2009). The difference in the patterns in juvenile growth of chum salmon between the eastern and western Pacific Ocean populations indicates that conditions in the 1990 s were more favorable for juvenile chum salmon in the western North Pacific than in the eastern North Pacific Ocean. Declines in zooplankton biomasses were documented in both regions of the North Pacific Ocean from the mid-1970s to the early 1990 s but remained $50 \%$ to $300 \%$ higher in the western North Pacific (Sugimoto and Tadokoro, 1997). Lower ocean productivity in the eastern Pacific may have accounted for the lower juvenile growth of the two chum salmon populations in our study during the 1980s and 1990s. We could not include indices of zooplankton biomass in our models because sufficient data were not available.

In our study, increases in size at maturity in the 1990s were linked to increases in immature growth. However, in the validations with reserved data, our models did not capture the entire increase in the $1^{\text {st }}$ and $2^{\text {nd }}$ immature years of growth for Fish Creek and Quilcene River chum salmon. Alternative conditions may exist that can explain the increase in immature growth in the mid-1990s. For example, the annual growth during age-0.1, 0.2, and 0.3 immature stages measured on the scales of adult chum salmon from Korea was positively correlated with zooplankton biomass in the Bering Sea (Seo et al., 2006), thus establishing a potential pathway for climate-induced changes in growth. Helle and Fukuwaka (2009) found a strong positive correlation between body size of maturing chum salmon from the eastern North Pacific and Japan and the spring and summer sea temperatures in the southeastern Bering Sea for the period 1977-1994, but weak and often negative correlations during the 19601976 and 1995-2006 periods. Decadal-scale changes in growth of N. American chum salmon may be related to shifts in their ocean distribution, e.g., northwestward shifts into the Bering Sea during summer in warm periods vs. remaining in the GOA during cool periods. Additional factors, such as zooplankton biomass and prey diversity, need to be investigated to determine the cause of increases in body size in the mid-1990s.

\section{Growth and abundance}

Evidence of density-dependent growth was detected in the juvenile chum salmon from Fish Creek, but not in those from Quilcene River. One explanation for this discrepancy in growth patterns may be the much higher abundance of pink and chum salmon in SE in comparison with WA and OR during our study period. In fact since 1995, the harvest of pink and chum salmon has been 5 to 12 times higher in the GOA region than in WA, OR, and BC combined (Eggers et al. ${ }^{1}$ ). Annually, Alaska hatcheries release approximately 1.5 billion juvenile salmon into the Pacific Ocean (Alaska Department of Fish and Game, available at website, data obtained in September 2012) and the primary species released are pink and chum salmon. Pink salmon are primarily released from Prince William Sound hatcheries, whereas chum salmon are the primary species released from hatcheries in $\mathrm{SE}$. In the waters along the Japan Sea coast of Honshu, Japan, where hatcheries release 100-300 million juvenile chum salmon annually, the relative weight of juvenile chum salmon stomach contents decreased as their density increased-a finding that was postulated to be the result of juvenile chum salmon depleting prey abundances (Fukuwaka and Suzuki, 2000). Similarly, early marine growth of Atlantic salmon (Salmo salar) from the Miramichi River in eastern Canada was inversely related to subsequent recruitment (Friedland et al., 2009). We found an inverse relationship between the mean body length of juvenile chum salmon and the surface trawl catch of juvenile pink and chum salmon from continental shelf waters off Icy Point in the GOA from 1997 to 2011 indicating density-dependent effects on growth. However, these surface-trawl-caught juvenile salmon were the length of the chum salmon in our study during the early juvenile stage and may not represent processes affecting growth later in life while chum salmon in the GOA.

Pink salmon abundance consistently influenced the immature growth of both populations of chum salmon, except in the $1^{\text {st }}$ immature year of Quilcene River chum salmon. This finding was consistent with that of previous studies of the influence of pink salmon on the growth of chum salmon (Ivankov and Andreyev, 1971; Salo, 1991; Bugaev et al., 2001; Kaeriyama et al., 2007; Agler et al., 2013). This observation was not surprising because pink salmon are the most abundant North American species of Pacific salmon (Eggers et al. ${ }^{1}$ ). However, chum salmon mature at multiple ages within a brood and are likely more abundant as immature individuals than the maturing pink salmon. Other studies have documented the effects of pink salmon abundance on the feeding of chum salmon. In oddyears of higher pink salmon abundances in the ocean, chum salmon were observed to consume less prey (Ivankov and Andreyev, 1971; Salo, 1991), shift their diet to less 
nutritious prey (Salo, 1991), and switch from eating crustacean zooplankton to eating gelatinous zooplankton (Tadokoro et al., 1996). From these studies it appears that the influence of pink salmon abundance may be greater than that of chum salmon because of their high population levels, fast growth rates, high degree of diet overlap with other salmon species, as well as their preference for lower trophic level prey, and their early migration to sea (Ruggerone and Nielsen, 2004).

Differences in the influence of pink salmon population abundances on growth of the $1^{\text {stimmature stage of }}$ chum salmon from the 2 populations investigated may be the result of differences in the migration and distribution of age 0.1 chum salmon. The SW2 of Fish Creek chum salmon was inversely related to the abundance of maturing pink salmon and age-0.1 chum salmon from SE to AP, whereas Quilcene River chum salmon were more significantly correlated with the abundance of immature age- 0.1 chum salmon from Asia. Chum salmon from WA and SE reside primarily in the eastern North Pacific and GOA (Urawa et al., 2009). However, $70 \%$ of the age- 0.1 chum salmon along the $145^{\circ} \mathrm{W}$ longitude from $48^{\circ} \mathrm{N}$ to $53^{\circ} \mathrm{N}$ during February were of SE origin and less than $1 \%$ were of WA origin (Beacham et al., 2009). Pink salmon are more abundant farther north in Prince William Sound than in SE or WA. That is, the southern-origin chum salmon were not likely distributed as far west or north as their northern conspecifics at age-0.1.

For both stocks, growth during the $2^{\text {nd }}$ immature stage was inversely related to chum and pink salmon abundance from British Columbia to Southeast Alaska, and growth during the maturing life stage was inversely related to maturing chum salmon from Asia. These results indicate possible co-occurrence of these 2 North American chum salmon populations in the ocean during their $2^{\text {nd }}$ immature life stage. To address similarities and differences in the migration routes of summer and fall chum salmon, a comparison of marine growth could be made between summer and fall chum salmon from the same river or area.

Several direct and indirect mechanisms exist that cause salmon to compete for resources in the ocean, particularly because the different species of Pacific salmon have a high degree of overlap in prey and habitat (Myers et al., 2007). Physical and biological conditions in the marine environment have direct and indirect influences on density-dependent growth through their influences on feeding and metabolic rates (Davis et al. ${ }^{4}$ ). In salmon, behavioral responses to competition or interference include reduced feeding, prey switching, and migration (Azumaya and Ishida, 2000; Davis et al., 2009). In addition to direct interaction, there may also be indirect density-dependent interactions among pink and chum salmon that could affect growth of chum salmon. For example, while although the density of pink salmon was higher in odd-numbered years in the Bering Sea, the growth of chum salmon was also higher (Azumaya and Ishida, 2000). This may be explained by the observation that in odd years, chum salmon are more likely to move from the Bering Sea to the eastern North Pacific Ocean (Azumaya and Ishida, 2000) - a behavior that we interpret as a response to avoid interaction with Asian-origin pink salmon. In the eastern North Pacific Ocean, chum salmon were more abundant and consumed lower quality prey (gelatinous zooplankton) in odd-numbered years, whereas in evennumbered years chum salmon abundance was lower and they consumed higher quality prey (squid and fish; Tadokoro et al., 1996), indicating an indirect effect of pink salmon abundance in the Bering Sea on the intra-specific competition of chum salmon in the eastern North Pacific Ocean. The ability of chum salmon to display plasticity in migration and feeding patterns may also be an adaptive response to more effectively reduce the impact of density on growth.

\section{Growth and climate}

Contrary to our hypotheses, a shallower mixed layer depth in the previous winter at the inner continental shelf of the northern GOA was not associated with an increase in growth. An early and stronger stratification of depth in the spring favors primary production in the middle shelf of the GOA (Henson, 2007). Therefore, water column stability during spring rather than deeper mixing during winter may influence prey densities in the surface layers where juvenile chum salmon feed and may favor their growth.

As anticipated, a fall phytoplankton bloom, which was generally followed by a peak in secondary productivity, as indexed by lower wind speed in September and October, was associated with an increase in the late juvenile growth of Fish Creek chum salmon. However, the index was not correlated with the late juvenile growth of Quilcene River chum salmon. In the GOA, a bloom of phytoplankton can occur during September and October but does not occur every year (Cooney, 2005). The fall bloom is initiated when fall winds deepen the mixed layer and resupply nutrients to the photic zone. Once nutrients are added to surface waters, a stratification of the water column is required before a fall bloom can occur (Cooney, 2005). Thus, a fall bloom is only possible in those years when wind speeds in September and October are not excessive.

Cooler late summer and fall SSTs were associated with an increase in growth during the $2^{\text {nd }}$ immature stage for the Fish Creek chum salmon, but growth was more strongly correlated with population abundance. Immature growth of western Alaska chum salmon was negatively correlated with GOA SSTs from 1965 to 2006 (Agler et al., 2013). This pattern might be explained by the fact that salmon in the eastern North Pacific Ocean and eastern Bering Sea are consuming higher quality prey in cool years (Aydin et al., 2000; Coyle et al., 2011). Specifically, in the eastern Bering Sea, chum salmon consumed primarily euphausiids in cold years and walleye pollock (Gadus chalcogrammus) in warm years (Coyle et al., 2011). Similarly, during the cold years 1996 and 1998 chum salmon were larger, 
and their diets consisted of proportionately more gonatid squid (Berryteuthis anonychus) (Aydin et al., 2000). In addition, it has also been suggested that differences in diet and growth of chum salmon may have been the result interannual variations in the summer latitudinal sea surface temperature minimum (warmer north and cooler south of the boundary) in the North Pacific Ocean. Salmon in the high seas adapt to climateinduced changes in their prey resources by switching their diets either within or between trophic levels (Kaeriyama et al. 2004).

After accounting for density-dependent effects, growth was positively related to SST. Different possible mechanisms exist for immature growth to increase with warmer summer SSTs and negative PDO events (cooler than average winters) in earlier years. For example, different physical phenomena (e.g., eddies, wind patterns, El Niño events) may transport nutrients into oceanic water of the North Pacific Ocean. Predominant among such phenomena are eddies, which form in waters above the continental shelf and slope in the eastern North Pacific Ocean (Ladd et al., 2005). In the cores of these eddies, iron and nitrate are transported from the sea floor to surface waters (Johnson et al., 2005) and these transported nutrients result in phytoplankton blooms inside the eddies as they move into oceanic waters at a rate of a few months to 5 years (Ladd, 2007). Zooplankton species are similarly transported from the shelf into the GOA (Mackas and Galbraith, 2002a). These eddies form more frequently in warmer years and during El Niño events (Crawford and Whitney, 1999). In a winter with a negative PDO, there is a northerly wind pattern in the eastern North Pacific (Mantua et al., 1997) and these winds may push these eddies off the shelf and into oceanic waters. Brodeur and Ware (1992) documented positive correlations between the intensity of the winter winds and subsequent summer zooplankton biomass in the subarctic gyre within the 1956-1962 and 1988-1989 year periods. In addition to the effect of eddies and wind on the productivity of oceanic waters, El Niño events can lead to a transport of heat and zooplankton from the equator that can reach the subarctic waters of the North $\mathrm{Pa}$ cific Ocean in 1 year and remain for 2 years (Mackas and Galbraith, 2002b). These events of increased ocean productivity may initiate and perpetuate a strong year class of a given prey taxon with a two-year life span. Finally, climate may also have a lag effect on growth through the lag effects of climate on mortality, bioenergetics, predation, competition, prey switching, distribution, and recruitment that influence growth, abundance, or the relationship of growth and abundance. Uncertainties in regard to the true mechanisms driving the annual variation in the growth of chum salmon support the use of a model with an error correction time series (Noakes et al. 1987).

No climate-related changes in growth were detected during the maturing life stage for the Quilcene stock. Our index of growth in length may not capture the total effects of climate or population abundance on growth. The lack of a significant relationship between maturing growth and climate indices in this study may be explained by the fact that during this stage, salmon growth favors an increase in body weight rather than length (Aydin et al., 2000), making it less possible for our length-based models to capture changes in growth. Alternatively, at larger body sizes, chum salmon switch from feeding on zooplankton to feeding on fish and gelatinous zooplankton not used by the other salmon species (Davis et al., 2009). This feeding plasticity may reduce the effects of intra- and interspecific competition for the larger, maturing chum salmon.

\section{Caveats}

Our model with the error correction that incorporated the lag structures of the model residuals and climate did not adequately predict the values of the reserved observations for SW2 of the Fish Creek chum salmon and SW3 of the Quilcene River chum salmon. The error correction component may have been incorrectly specified, the growth and abundance relationships may have undergone temporal change, or the time series may have been too variable or too short to provide reliable coefficient estimates. The error correction did not account for the total increase in growth in the late 1990s and early 2000s. Helle et al. (2007) suggested that the increase in body size of chum salmon in the mid-1990s during a period of high population abundance was due to an increase in the carrying capacity for salmon in the North Pacific Ocean. This question merits further investigation.

Although uncertainty exists regarding whether back-calculated abundance indices that are based on the numbers of returning salmon, marine mortality, and age composition are good indices for abundance earlier in life, the assumption that back-calculated salmon abundance was a metric of salmon abundance earlier in life was supported by a strong correlation between the abundances of juvenile pink salmon and the returns of adult pink salmon in the following year (Orsi et al. ${ }^{3}$ ). However, correlation does not imply causation. Nonetheless, it would have been preferable to base our analysis on a time series of actual abundance of juvenile and immature salmon at sea. This was not possible, because very few such time series exist and those that do exist were too short to be used for this study. Alternatively, at-sea estimates of abundance would likely be subject to large sampling uncertainty; hence the indices based on harvest and assumed mortality rates may actually be better.

\section{Implications for management}

During the first year at sea, size was considered a critical factor affecting marine mortality rates of salmon (Parker, 1971; Holtby et al., 1990). Size attained by the first winter at sea was also considered important in determining year-class strength (Beamish and Mahnken, 2001). We found that an increase in the abundance of ju- 
venile pink salmon from SE has the potential to reduce growth of Fish Creek chum salmon. Therefore, fishery and hatchery managers may wish to consider adjusting the number of pink salmon fry released from hatcheries into coastal waters in order to increase early growth and subsequent survival of juvenile chum salmon.

Climate during the first year at sea was strongly correlated with survival in salmon (Mueter et al., 2002; Martinson et al., 2009). We found that the late juvenile growth of chum salmon from Fish Creek increased as the velocity of surface winds decreased in the fallan indicator of the occurrence of fall phytoplankton blooms. Therefore, the wind velocity index in the northern GOA may be a useful predictor for the marine survival of chum salmon from the GOA.

This research provides insight into factors that affect growth and size-at-maturity of chum salmon for different life stages of 2 geographically separated stocks in the eastern North Pacific Ocean. We found evidence for density-dependent growth during the juvenile, immature, and maturing life stages, indicating that density-dependent influences on growth at sea influence final size at maturity of chum salmon. Results of our correlation study were viewed with caution but as possible mechanisms for changes in growth and final size-at-maturity of chum salmon.

\section{Acknowledgments}

Funding and support for this project was received from the Alaska Fisheries Science Center in Juneau, Alaska and the Advanced Studies Program, Professional Development program of the National Oceanic and Atmospheric Administration. We greatly appreciate the assistance of all the people that helped with field collection throughout the years and the assistance of the Alaska Department of Fish and Game in Ketchikan and the U.S. Fish and Wildlife Service at the Quilcene National Fish Hatchery in Quilcene, Washington. We appreciate the constructive comments from Phil Mundy, Ed Farley, and Lisa Eisner. We also thank the anonymous reviewers for their thoughtful suggestions that greatly improved the manuscript.

\section{Literature cited}

Agler, B. A., G. T. Ruggerone, L. I. Wilson, and F. J. Mueter. 2013. Historical growth of Bristol Bay and Yukon River, Alaska chum salmon (Oncorhynchus keta) in relation to climate and inter- and intra-specific competition. DeepSea Res., II 94:165-177. Article

Arnold, E. L., Jr.

1951. An impression method for preparing fish scales for age and growth analysis. Prog. Fish-Cult. 13:11-16. Article

Auburn, M. E., and S. E. Ignell.

2000. Food habits of juvenile salmon in the Gulf of Alaska July-August 1996. N. Pac. Anadr. Fish Comm. Bull. 2:89-97.
Aydin, K., Myers, K., and R. Walker.

2000. Variation in summer distribution of the prey of $\mathrm{Pa}-$ cific salmon Oncorhynchus spp. in the offshore Gulf of Alaska in relation to oceanographic conditions, 1994-98. N. Pac. Anadr. Fish Comm. Bull. 2:43-54.

Azumaya, T., and Y. Ishida.

2000. Density interactions between pink salmon (Oncorhynchus gorbuscha) and chum salmon (O. keta) and their possible effects on distribution and growth in the North Pacific Ocean and Bering Sea. N. Pac. Anadr. Fish Comm. Bull. 2:165-174.

Beacham, T. D., J. R. Candy, S. Sato, S. Urawa, K. D. Le, and M. Wetklo.

2009. Stock origins of chum salmon (Oncorhynchus keta) in the Gulf of Alaska during winter as estimated with microsatellites. N. Pac. Anadr. Fish Comm. Bull. $5: 15-23$.

Beamish, R. J., and C. Mahnken.

2001. A critical size and period hypothesis to explain natural regulation of salmon abundance and the linkage to climate and climate change. Prog. Oceanogr. 49:423-437. Article

Beamish, R. J., and D. R. Bouillon.

1993. Pacific salmon production trends in relation to climate. Can. J. Fish. Aquat. Sci. 50:1002-1016. Article

Bigler, B. S., D. W. Welch, and J. H. Helle.

1996. A review of size trends among North Pacific salmon (Oncorhynchus spp.). Can. J. Fish. Aquat. Sci. 53:455-465. Article

Brodeur, R. D., and D. M. Ware.

1992. Long-term variability in zooplankton biomass in the subarctic Pacific Ocean. Fish. Oceanogr. 1:32-39. Article

Bugaev, V. F., D. W. Welch, M. M. Selifonov, L. E. Grachev, and J. P. Eveson.

2001. Influence of the marine abundance of pink salmon (Oncorhynchus gorbuscha) and sockeye salmon (O. nerka) on growth of Ozernaya River sockeye. Fish. Oceanogr. 10:26-32. Article

Cooney, R. T.

2005. Biological and chemical oceanography. In The Gulf of Alaska: biology and oceanography (P. R. Mundy, ed.), p. 49-58. Alaska Sea Grant College Program, Univ. Alaska, Fairbanks, AK.

Coyle, K. O., L. B. Eisner, F. J. Mueter, A. I. Pinchuk, M. A. Janout, K. D. Cieciel, E. V. Farley, and A. G. Andrews.

2011. Climate change in the southeastern Bering Sea: impacts on pollock stocks and implications for the oscillating control hypothesis. Fish. Oceanogr. 20:139-156. Article

Crawford, W. R., and F. A. Whitney.

1999. Mesoscale eddy swirl with data in the Gulf of Alaska. EOS Trans. Am. Geophys. Union 80:365-370. Article

Dahl, K.

1909. The assessment of age and growth in fish: a short account of the development of present methods and main litterature on the subject. Int. Rev. Gesamten Hydrobiol. Hydrogr. 2:758-769. Article

Davis, N. D., A. V. Volkov, A. Y. Efimkin, N. A. Kuznetsova, J. L. Armstrong, and O. Sakai.

2009. Review of BASIS salmon food habits studies. N. Pac. Anadr. Fish Comm. Bull. 5:197-208. 
Eggers, D. M.

2009. Historical biomass of pink, chum, and sockeye salmon in the North Pacific Ocean. Am. Fish. Soc. Symp. 70:267-306.

Francis, R. C, and S. R. Hare.

1994. Decadal-scale regime shifts in the large marine ecosystems of the North-east Pacific: a case for historical science. Fish. Oceanogr. 3:279-291. Article

Freeland, H., K. Denman, C. S. Wong, F. Whitney, and R. Jacques.

1997. Evidence of change in the winter mixed layer in the northeast Pacific Ocean. Deep-Sea Res. Oceanogr. 4:2117-2129. Article

Friedland, K. D., D. Moore, and F. Hogan.

2009. Retrospective growth analysis of Atlantic salmon (Salmo salar) from the Miramichi River, Canada. Can. J. Fish. Aquat. Sci. 66:1294-1308. Article

Fukuwaka, M., and M. Kaeriyama.

1997. Scale analyses to estimate somatic growth in sockeye salmon Oncorhynchus nerka. Can. J. Fish. Aquat. Sci. 54:631-636. Article

Fukuwaka, M., and T. Suzuki.

2000. Density-dependence of chum salmon in coastal water of the Japan Sea. N. Pac. Anadr. Fish Comm. Bull. $2: 75-81$

Hare, S. R., and R. C. Francis.

1995. Climate change and salmon production in the northeast Pacific Ocean. Can. Spec. Publ. Fish. Aquat. Sci. 121:357-372.

Hare, S. R., and N. J. Mantua.

2000. Empirical evidence for North Pacific regime shifts in 1977 and 1989. Prog. Oceanogr. 47:103-145. Article

Hartt, A. C., and M. B. Dell.

1986. Early oceanic migration and growth of juvenile Pacific salmon and steelhead trout. Int. N. Pac. Fish. Comm. Bull. 46, 105 p.

Heinl, S. C.

2005. Chum salmon stock status and escapement goals in southeast Alaska. In Stock status and escapement goals for salmon stocks in southeast Alaska 2005. Alaska Dep. Fish Game, Spec. Publ. 05-22 (J. A. Der Hovanisian and H. J. Geiger, eds.), p. 191-209. Alaska Dep. Fish Game, Anchorage, AK.

Helle, J. H.

1979. Influence on marine environment on age and size at maturity, growth, and abundance of chum salmon, Oncorhynchus keta (Walbaum), from Olsen Creek, Prince William Sound, Alaska. Ph.D. thesis, 118 p. Oregon State Univ., Corvallis, OR.

1989. Relation between size-at-maturity and survival of progeny in chum salmon, Oncorhynchus keta (Walbaum). J. Fish Biol. 35(suppl. A):99-107. Article

Helle, J. H., and M. Fukuwaka.

2009. Body size of maturing salmon in relation to sea surface temperatures in the eastern Bering Sea. N. Pac. Anadr. Fish Comm. Bull. 5:303-319.

Helle, J. H., and M. S. Hoffman.

1998. Changes in size and age at maturity of two North American stocks of chum salmon (Oncorhynchus keta) before and after a major regime shift in the North Pacific Ocean N. Pac. Anadr. Fish Comm. Bull. 1:81-89.

Helle, J. H., E. C. Martinson, D. M. Eggers, and O. Gritsenko. 2007. Influence of salmon abundance and ocean conditions on body size of Pacific salmon. N. Pac. Anadr. Fish Comm. Bull. 4:289-298.
Henson, S. A.

2007. Water column stability and spring bloom dynamics in the Gulf of Alaska. J. Mar. Res. 65:715-736. Article Hilborn, R., and D. Eggers.

2000. A review of the hatchery programs for pink salmon in Prince William Sound and Kodiak Island, Alaska. Trans. Am. Fish. Soc. 129:333-350. Article

Holtby, L., B. Andersen, and R. Kadowaki.

1990. Importance of smolt size and early ocean growth to interannual variability in marine survival of coho salmon Oncorhynchus kisutch. Can. J. Fish. Aquat. Sci. 47:2181-2194. Article

Ivankov, V. N., and V. L. Andreyev.

1971. The South Kuril chum (Oncorhynchus keta (Walb.)): ecology, population structure and the modeling of the population. J. Ichthyol. 11:511-524.

Johnson, W. K., L. A. Miller, N. E. Sutherland, and C. S. Wong. 2005. Iron transport by mesoscale Haida eddies in the Gulf of Alaska. Deep-Sea Res. Part II, 52:933-953. Article

Kaeriyama, M.

1998. Dynamics of chum salmon, Oncorhynchus keta, populations released from Hokkaido, Japan. N. Pac. Anadr. Fish Comm. Bull. 1:90-102.

Kaeriyama, M., M. Nakamura, R. Edpalina, J. R. Brower, H. Yamaguchi, R. V. Walker, and K. W. Myers.

2004. Changes in feeding ecology and trophic dynamics of Pacific salmon (Oncorhynchus spp.) in the central Gulf of Alaska in relation to climate events. Fish. Oceanogr. 13:197-207. Article

Kaeriyama, M., A. Yatsu, M. Noto, and S. Saitoh.

2007. Spatial and temporal changes in the growth patterns and survival of Hokkaido chum salmon populations in 1970-2001. N. Pac. Anadr. Fish Comm. Bull. $4: 251-256$.

Kalnay, E., M. Kanamitsu, R. Kistler, W. Collins, D. Deaven, L. Gandin, M. Iredell, S. Saha, G. White, J. Woollen, Y. Zhu, M. Chelliah, W. Ebisuzaki, W. Higgins, J. Janowiak, K. C. Mo, C. Ropelewski, J. Wang, A. Leetmaa, R. Reynolds, M. Chelliah, W. Ebisuzak, W. Higgans, J. Janowiak, K. C. Mo, C. Ropelewski, J. Wang, R. Jenne, and D. Joseph.

1996. The NCEP/NCAR 40-year reanalysis project. Bull. Am. Meteorol. Soc. 77:437-471. Article

Kobayashi, T.

1961. Biology of chum salmon, Oncorhynchus keta (Walbaum), by the growth formula of scale. Sci. Rep. Hokkaido Fish Hatch. 16:1-102. [In Japanese, English summary.]

Koski, K V.

1975. The survival and fitness of two stocks of chum salmon (Oncorhynchus keta) from egg deposition to emergence in a controlled-stream environment at Big Beef Creek. Ph.D. thesis, 213 p. Univ. Washington, Seattle, WA.

Ladd, C.

2007. Interannual variability of the Gulf of Alaska eddy field. Geophys. Res. Lett. 34, L11605. Article

Ladd, C., N. B. Kachel, C. W. Mordy, and P. J. Stabeno.

2005. Observations from a Yakutat eddy in the northern Gulf of Alaska. J. Geophys. Res. 110, C03003. Article

Lee, R. M.

1920. A review of the methods of age and growth determination in fishes by means of scales. Fish. Invest., II 4:1-32

Lehmann, E. L.

1959. Testing statistical hypotheses, 369 p. John Wiley and Sons, New York. 
Logerwell, E. A., N. Mantua, P. W. Lawson, R. C. Francis, and V. N. Agostini.

2003. Tracking environmental processes in the coastal zone for understanding and predicting Oregon coho (Oncorhynchus kisutch) marine survival. Fish. Oceanogr. 12:554-568. Article

Mackas, D. L., and M. D. Galbraith.

2002a. Zooplankton distribution and dynamics in a North Pacific eddy of coastal origin: I. Transport and loss of continental margin species. J. Oceanogr. 58:725-738.

2002b. Zooplankton community composition along the inner portion of Line P during the 1997-1998 El Niño event. Prog. Oceanogr. 54:423-437. Article

Mantua, N. J., S. R. Hare, Y. Zhang, J. M. Wallace, and R. C. Francis.

1997. A Pacific interdecadal climate oscillation with impacts on salmon production. Bull. Am. Meteorol. Soc. 78:1069-1079. Article

Martinson, E. C., J. H. Helle, D. L. Scarnecchia, and H. H. Stokes.

2008. Density-dependent growth of Alaska sockeye salmon in relation toclimate-oceanic regimes, population abundances, and body size, 1925 to 1998. Mar. Ecol. Prog. Ser. 370:1-18. Article

2009. Growth and survival of sockeye salmon (Oncorhynchus nerka) from Karluk Lake and River, Alaska, in relation to climatic and oceanic regimes and indices, 19222000. Fish. Bull. 107:488-500.

Morita, K., S. H. Morita, and M. Fukuwaka.

2006. Population dynamics of Japanese pink salmon (Oncorhynchus gorbuscha): are recent increases explained by hatchery programs or climate variation? Can. J. Fish. Aquat. Sci. 63:55-62. Article

Mueter, F. J., R. M. Peterman, and B. J. Pyper.

2002. Opposite effects of ocean temperature on survival rates of 120 stocks of Pacific salmon (Oncorhynchus spp.) in northern and southern areas. Can. J. Fish. Aquat. Sci. 59:456-463. Article

Myers, K. W., N. V. Klovach, O. F. Gritsenko, S. Urawa, and

T. C. Royer.

2007. Stock-specific distributions of Asian and North American salmon in the open ocean, interannual changes, and oceanographic conditions. N. Pac. Anadr. Fish Comm. Bull. 4:159-177.

Noakes, D., D. W. Welch, and M. Stocker.

1987. A time series approach to stock recruitment analysis: transfer function noise modeling. Nat. Resour. Model. 2:213-233.

Parker, R. R.

1968. Marine mortality schedules of pink salmon of the Bella Coola River, central British Columbia. J. Fish. Res. Board Can. 25:757-794. Article

1971. Size selective predation among juvenile salmonid fishes in British Columbia inlet. J. Fish. Res. Board Can. 28:1503-1510. Article

Reed, R. K., and J. D. Schumacher.

1986. Physical oceanography. In The Gulf of Alaska: physical environment and biological resource (D. W. Hood and S. T. Zimmerman, eds.), p. 57-75. Alaska Office, Ocean Assessment Division, NOAA, Anchorage, AK.

Ruggerone, G. T., R. M. Peterman, B. Dorner, and K. W. Myers.

2010. Magnitude and trends in abundance of hatchery and wild pink salmon, chum salmon, and sockeye salmon in the North Pacific Ocean. Mar. Coast. Fish. 2:306-328. Article
Ruggerone, G. T., and J. L. Nielsen.

2004. Evidence for competitive dominance of pink salmon (Oncorhynchus gorbuscha) over other salmonids in the North Pacific Ocean. Rev. Fish Biol. Fish. 14:371-390. Article

Salo, E. O.

1991. Life history of chum salmon (Oncorhynchus keta). In Pacific salmon life histories. (C. Groot and L. Margolis, eds.), p. 231-309. UBC Press, Vancouver, Canada.

Sarkar, N.

2007. Mixed layer dynamics along the Seward line in the northern Gulf of Alaska. Ph.D. thesis, 71 p. Old Dominion Univ., Norfolk, VA.

Schroder, S. L.

1982. The influence of intrasexual competition on the distribution of chum salmon in an experimental stream. In Proceedings of the salmon and trout migratory behavior symposium; 3-5 June 1981 (E. L. Brannon and E. O. Salo, eds.), p. 275-285. School Fish., Univ. Washington, Seattle, WA.

Seeb, L. W., P. A. Crane, C. M. Kondzela, R. L. Wilmot, S. Urawa, N. V. Varnavskaya, and J. E. Seeb.

2004. Migration of Pacific Rim chum salmon on the high seas: insights from genetic data. Environ. Biol. Fish. 69:21-36. Article

Seo, H., S. Kim, K. Seong, and S. Kang.

2006. Variability in scale growth rates of chum salmon (Oncorhynchus keta) in relation to climate changes in the late 1980s. Prog. Oceanogr. 68:205-216. Article

Spies, R. B., and T. Weingartner.

2007. Long-term change. In Long-term ecological change in the northern Gulf of Alaska (R. B. Spies, ed.), p. 259418. Elsevier, Oxford, UK.

Sugimoto, S., and K. Tadokoro.

1997. Interannual-interdecadal variations in zooplankton biomass, chlorophyll concentration and physical environment in the subarctic Pacific and Bering Sea. Fish. Oceanogr. 6:74-93. Article

Tadokoro, K., Y. Ishida, N. D. Davis, S. Ueyanagi, and T. Sugimoto.

1996. Change in chum salmon (Oncorhynchus keta) stomach contents associated with fluctuation of pink salmon (O. gorbuscha) abundance in the central subarctic Pacific and Bering Sea. Fish. Oceanogr. 5:89-99. Article

Urawa, S., S. Sato, P. A. Crane, B. Agler, R. Josephson, and T. Azumaya.

2009. Stock-specific ocean distribution and migration of chum salmon in the Bering Sea and North Pacific Ocean. N. Pac. Anadr. Fish Comm. Bull. 5:131-146.

van de Berghe, E. P., and M. R. Gross.

1984. Female size and nest depth in coho salmon (Oncorhynchus kisutch). Can. J. Fish. Aquat. Sci. 41: 204-206. Article

Wertheimer, A. C.

1997. Status of Alaska salmon. In Pacific salmon and their ecosystems: status and future options (D. J. Stouder, P. A. Bisson, and R. Naiman, eds.), p. 179-199. Springer Science+Business Media, Dordrecht, Netherlands.

Zavolokin, A. V., E. A. Zavolokin, and Y. N. Khokhlov.

2009. Changes in size and growth of Anadyr chum salmon (Oncorhynchus keta) from 1962-2007. N. Pac. Anadr. Fish Comm. Bull. 5:157-163.

Zhang, Y., J. M. Wallace, and D. S. Battisti.

1997. ENSO-like interdecadal variability: 1900-93. J. Clim. 10:1004-1020. Article 